\title{
China's digital media industries and the challenge of overseas markets
}

\author{
By Michael Keane
}

\begin{abstract}
The influence of China on the world stage is beyond question; however, this influence is most evident in the realm of economics. Since the early 2000s China's media and cultural industries have made a concerted effort to enter international markets. In recent years China's leading online and digital platforms have become linked to the so-called 'culture going out' campaign; they contribute to 'the call of government' by revitalizing Chinese cultural products/services and promoting them through online consumption experiences on their affiliated platforms. This paper examines the extent of these Chinese digital companies' capabilities in the great rejuvenation of China's culture. The paper also considers the problem of reporting on the reception of China's film and television outside China. It argues that while online platforms are getting the message out, Chinese products are primarily targeted at the domestic audience and the already converted, those in the Chinese diaspora. This online model of dissemination in turn has implications for how academics use the term 'media industry.'
\end{abstract}

Keywords: going out, digital media, film, television, cultural empowerment

\section{Introduction}

During the 1990s in the Peoples' Republic of China (hereafter PRC), the catchphrase 'please come in' (qing jinlai) resonated within government policy circles ${ }^{\mathrm{i}}$. Many transnational companies ventured in, taking advantage of preferential policies to set up manufacturing processing facilities, mostly in southern Guangdong province, and mostly exploiting China's cheap labour. ${ }^{\text {ii }}$ Foreign media content also went in; foreign television, cinema and animations were accessible to many millions of Chinese during the mid-1990s despite the existence of entry quotas and censorship. More content flooded in through the black market: VCDs, DVDs and later illegal downloads. From the turn of the century, however, with the government actively promoting the 'going out' (zou chuqu) of Chinese culture and media, foreigners encountered new restrictions. Since 2003, the Chinese government has assisted the export of its media and cultural products with a range of tax incentives and subsidies. ${ }^{\text {iii }}$ One of the main aims of the going out strategy is to take a message to the world, a message about 
a great civilisation, a strong united nation, and a resourceful people. By the mid-2000s the government was investing something like US\$10 billion a year on external propaganda, although as David Shambaugh suggests, this number is extremely hard to verify, as is the number of people actually tuning into the message. ${ }^{\text {iv }}$

In a time when so many public resources are directed to internationalisation, it is worth considering how much of the massive government support converts into influence. What measure of success are China's institutions, enterprises, cultural projects and products achieving? Outside China, who is actually watching Chinese TV, and where? How are most people accessing Chinese content? And does the rejuvenation of the Chinese film industry, measured by the box office success of blockbusters such as Operation Mekong (meigong he xing dong) (dir. Dante Lam 2016), Operation Red Sea (meigong he xindong) dir. Dante Lam 2018), and Wolf Warrior II (zhanlang) (dir. Wu Jing, 2017) translate into external cultural influence or 'soft power'?

This paper considers the ongoing digital transformation of film and television industries in China. Drawing on industry analysis, surveys, and academic critique the paper presents the case that digital platforms are a new vanguard of Chinese 'cultural soft power', both domestically and internationally. It begins by noting the governmental imperative behind the 'culture going out' project and links this to 'cultural empowerment' (wenhua qiangguo). The discussion then notes the relative failure of the going out project to date outside the mainland, noting the problems of statistical validity in the cultural and creative industries generally, and the media content industries more specifically. Data is presented from a variety of sources to illustrate this, including a survey conducted by the writer. The data refers to both film and television industries but concludes that the most successful dissemination channel for China's media content outside China is YouTube. In this context the paper suggests that research needs to reassess the weighting placed on traditional film and television 'industry' metrics, and that the term industry be extended to take account of the widespread distribution and critique of content via social media platforms.

In effect, technology is changing the way that audio-visual culture is produced, distributed and consumed. Technology is not only changing the culture of production and its industrial practices, but it may enhance the chances of monetization and recognition. The paper looks how digital platforms are 'riding the wave' of content provision, in particularly noting the ascendancy of BAT, Baidu, Alibaba and Tencent and their ambitions to develop cultural assets that resonate with young demographics. The final section returns to the question of how best to evaluate the success or otherwise of China's outward-bound mission, suggesting that online platforms, streaming services and user generated content, more than traditional outlets are the future, a view that concords with developments elsewhere in the world.

\section{Cultural power, industries and the great revitalization}

Most observers of Chinese politics are familiar with the Chinese Dream, a slogan that has come front and centre into policy language; it adorns billboards throughout China's cities and towns, as well as work sites and subways. The Chinese Dream heralds a rejuvenated China 
and was announced by Xi Jinping in 2012, although first coined by the senior policy advisor Zheng Bijian in 2005. ${ }^{\vee}$ The timeline for realisation is 2049, symbolically a hundred years after the founding of the republic, or 'new China'. Behind the Chinese Dream are numerous explicit references to power: in the cultural sphere terms like 'cultural soft power' (wenhua ruanshili) 'cultural empowerment' (wenhua qiangguo), 'cultural security' (wenhua anquan), and 'cultural self-confidence' (wenhua zixin) proliferate. After three decades of economic reform in which China has made systemic and sustained inroads into the global economy, power is unapologetically equated with national rejuvenation.

In bookstores like the Xidan Book market in Beijing one finds titles about the 'great powers' (i.e. European and US empires). The Chinese government, already counts the nation as a 'great power' (daguo) - and on the way to becoming a 'strong power' (qiangguo). Together with various treatises on power and empowerment there are the stories of China's new breed of digital entrepreneurs. Through their worldly exploits these entrepreneurs are demonstrating that China is a technologically advanced nation. At the same time, they are investing in the film and television industries, online streaming video, fin-tech, e-commerce logistics, data infrastructure, and in Virtual Reality and Artificial Intelligence.

Despite the variations around the uses of terminology — soft power, cultural power, self-confidence etc., one fact remains, China's global cultural presence has become more visible since the government endorsed the commercialization of online platforms and recognized their contribution to the 'going out' program. Many resources were directed towards increasing China's media presence in the world during the early 2000s, particularly in the light of the popularity of foreign cultural and media products in China, including South Korean and Japanese pop culture. ${ }^{\text {vi }}$ Wanning Sun has noted the justification of the 'going abroad' policy relative to the print media, particular in relation to correcting foreign 'perceptions of China'. vii Yuezhi Zhao demonstrates how 'depoliticization' of culture is foregrounded in China's culture 'going out' project, particular with respect to the championing of essentialist Chinese values like 'harmony' and 'the promotion of Confucius as China's ambassador', rather than Western-style contestations between antagonistic forces about the future direction of society. ${ }^{\text {vii }}$ Of course, one can argue that this is an explicit political strategy: build the image of China as a good global citizen, one that seeks to be a peacemaker rather than a coloniser.

Cultural soft power, now referred to as 'cultural empowerment' within senior policy circles in China, ${ }^{\text {ix }}$ has its legacy in the work of the US political scientist Joseph Nye Jnr. Nye's definition of soft power is frequently cited, namely a nation's 'culture (in places where it is attractive to others), its political values (where it lives up to them at home and abroad), and its foreign policies (where they are seen as legitimate and having moral authority). ${ }^{\mathrm{x}}$ Many academic accounts are accordingly weighted toward diplomacy and foreign affairs, the kind of elements that index a nation as attractive or admirable. ${ }^{\text {xi }}$ This understanding of soft power, however, does not address the central importance of cultural revitalization in China and beyond its borders, nor does it address the film, television and associated media content sectors.

The context for 'cultural soft power's' entry into the Chinese political lexicon is described by Ying Zhu in her 2012 study of CCTV. Zhu writes how in the early 2000s, Ren Xuean, then a producer working with CCTV, proposed a large-scale TV documentary series 
to capitalize on the mood of a rising China among China's politburo. The Rise of the Great

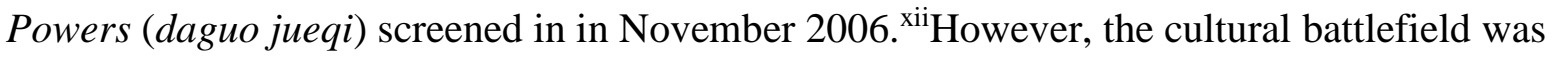
established in the mid-1990s in the wake of the struggles of the Chinese film industry to counter Hollywood's inroads ${ }^{\text {xiii }}$ as well as the State Administration of Radio Film and Television (SARFT)'s attempts to stem the influence of foreign TV dramas ${ }^{\mathrm{xiv}}$.

The government formally instituted the cultural industries (wenhua chanye) in 2001, the year that China's entered the World Trade Organization (WTO). The term 'cultural trade deficit' (wenhua maoyi chizi), which referred specifically to media content, was a stark reminder of China's lack of overseas success relative to the popularity of overseas media content in the PRC. ${ }^{x v}$ A national research center was established in Beijing in the mid-2000s dedicated to the task of collating data and making recommendations to the government concerning cultural trade. Reports emanated, mostly penned in the Blue Book (lanpi shu) consultancy style ${ }^{\mathrm{xvi}}$, offering individual sector analyses i.e. film, television, animation, music, while failing to take account for industry convergence and the fact that consumers were satisfying their desires for film and television consumption online. As noted above, Chinese digital entrepreneurs were quick to recognize such 'user' trends and have become the enablers of a new mode of industry in China, which Cunningham and Craig call 'social media entertainment.' ${ }^{\text {xvii }}$ I will return to this important point in the conclusion.

\section{Relative successes in the film and television sectors}

Infrastructure and overseas assets have helped the cause of the media content industries as we have come to know them. Chinese-owned cinema chains like AMC and Hoyts screen Chinese films in many overseas cities and some commentators in China have pointed to the fact that this kind of industrial acquisition model provides a way for Chinese film to reach new audiences in the same way that multiplexes in China have allowed international movies to connect with Chinese filmgoers. Yet Chinese movies have had mixed success in global markets. Aside from the occasional 'hit' by a leading filmmaker in the art film and festival circuit, the numbers just don't make great reading. The Zhang Yimou helmed co-production The Great Wall (2016-17) received disappointing ratings of 6/10 on IMDB, 35 percent on the Rotten Tomatoes site, and 5.4/ 10 on Douban, the Chinese online rating site. ${ }^{\text {xviii }}$ The Hollywood Reporter concluded that The Great Wall provided lessons for Sino-American productions, in particular 'the difficulties of finding stories that meld Eastern and Western characters and the challenges of blending crews, which in Wall's case meant hiring 100 interpreters and solving conflicts that allegedly took place among some below-the-line workers. 'xix As to whether or not The Great Wall advances China's cultural power, Ying Zhu cautions that 'it is a reminder that a big budget, star actors, and excessive visual effects do not magically translate into compelling stories, Hollywood or Chinese. The Great Wall has failed to advance anybody's power, financial or cultural. ${ }^{\mathrm{xx}}$

The film grossed only $\$ 34.8$ million in North America. In neighbouring South Korea, the box-office takings were less than $\$ 4$ million $^{\mathrm{xxi}}$ The problem with The Great Wall is undoubtedly its pretension: attempting to ingratiate a narrative about China's moral superiority on foreign audiences was always going to be a hard task. The transformation of 
the white-skinned selfish mercenary William played by Matt Damon into a self-sacrificing Chinese style hero, inspired by a beautiful female, Commander Lin Mae (Jing Tian), played to the Party line but failed to win over hearts and minds outside China. The mega blockbuster Wolf Warrior 2 (zhanlang), which evokes a rising China, likewise bombed in Korea, although this rejection may have been clouded by political disputes and sabre rattling associated with the THAAD missile crisis of 2016-17. The absurdity of the narrative in which the hero Leng Feng beats up the baddies, saves both locals and Chinese nationals, and even uses his smartphone (Chinese technological superiority) to record terrorist atrocities and transmit location details to the Chinese navy, which then launches a precision-guided missile, appears more like a parody film to many foreign viewers. As a leading western film critic writes: "Wolf Warrior 2" is for anyone who wishes more modern action movies were like bad Rambo rip-offs, only minus Stallone's charms, and amplified by Michael Bay-levels of souldead military/gun fetishism'. xxii

A partiality towards big budget martial arts genre has been a feature of Chinese filmmaking since the early 2000s, following the success of Crouching Tiger Hidden Dragon (2000), Hero (2002) Fearless (2006), Kung-Fu Hustle (2004) and The House of Flying Daggers (2004) While this genre established a visible presence for Chinese cinema internationally, on the back of notable precedents in Hong Kong cinema, a report conducted in 2011 found that more than a third of foreign audiences had never watched a Chinese movie. ${ }^{\text {xxiii }}$ However, these findings are turned on their head by later research, part of a longitudinal study of China's national image as portrayed through cinema. Conducted by a team of researchers at Beijing Normal University, the findings were published in 2018 in the English language newspaper, The China Daily. ${ }^{\text {xxiv }}$ The survey tested two hypotheses: (i) that US and Canadian respondents' impressions of Chinese films and their impressions of China's national image are consistent; and (ii) that the more respondents watch Chinese movies, the higher is their positive evaluation of China's national image. A total of 1208 and 312 surveys were returned in US and Canada respectively, with nominated ethnic groups being 'white', Asian, African-American, and 'other ethnic group.' In fact, $68.4 \%$ self-identified as 'white'. The survey found that overall $79.1 \%$ of people had watched one or more Chinese movies in the past three years, with $43.3 \%$ saying they had watched five or more.

The report identified barriers to understanding such as poor subtitling and lack of cultural familiarity but didn't ask any 'hard' questions in regard to state censorship or misgivings about propaganda laden content. The report dutifully concluded that movies were a better way to transmit understandings of China's national image than mainstream media or even the internet. However, the report makes no distinction regarding 'made-in-PRC' movies and those made in adjacent territories, or co-productions; it also assumes that the respondents identify a Chinese movie by dint of it featuring Chinese actors and producers, including Hong Kong and Taiwanese. In effect, in this analysis, the Karate Kid (2010), is ostensibly a Chinese movie, as are Stephen Chow co-productions including Journey to the West: Conquering the Demons (2013) and the Mermaid (2016) The highly successful Hong Kong offering Project Gutenberg (2018), which was filmed in Hong Kong, Vancouver, and Thailand, while not within the time frame of this report, represents another example of category confusion. As Chris Berry writes of transnational film production, 'the cast and 
crew might hold passports of different countries; and elements of the final product such as the music, the editing, special effects and so forth may be outsourced across national borders.' ${ }^{\mathrm{xxv}}$

Likewise, the survey's methodology of allocating eight genres (action, war, romance, comedy, science fiction, fantasy, thrillers and kung-fu) is interesting when we consider that such genres are not officially recognised within Chinese film-making. The report suggested, moreover, that US and Canadian audiences were tiring of the martial arts genre, with the exception being black Americans who were predisposed to this genre. ${ }^{x x v i}$ In fact, the highwater mark of the genre seemed to have passed some years earlier. Wendy Su notes that in 2012, no Chinese martial arts film achieved any significant measure of success.

Furthermore, by this time Chinese films had fallen far behind Indian and Korean films in the international market. China failed to register among the 'top thirty movie producers in the US market'. xxvii

A survey conducted by my research team in September 2018 reveals a slightly different picture of reception of Chinese audio-visual content. Our intent was to examine reception, or at least willingness to view Chinese audio-visual content in the Asia-Pacific, focusing on South Korea, Taiwan, Hong Kong SAR, Singapore, Malaysia, Indonesia and Australia. Our online survey received 1235 valid responses. ${ }^{\text {xxviii }}$ Most respondents in this survey were born in the PRC (513), followed by South Korea (207), Australia (56), HKSAR (52), Malaysia (43), Taiwan (41), Singapore (40), and Indonesia (30). Noting that the Beijing Normal survey didn't indicate a propensity to pay to view, we asked if people spent personal money on watching a Chinese movie in a cinema, paying to download e.g. video-on-demand, or paying to stream a Chinese title during the past twelve months. Out of a total of 279 respondents to this question, 193 responded that they didn't pay any money. In other words, they viewed Chinese content online for free. The most popular platform for viewing is YouTube, which features a great deal of Chinese language content including music, film, talk shows and television series (not subtitled in English).

In response to a more general question about reasons for 'unwillingness to view' Chinese film and television, respondents born in Taiwan and Hong Kong cited high propaganda content before 'a lack of production quality'; those in South Korea on the other hand were less deterred by propaganda and more concerned about production quality, cultural unfamiliarity, and lack of known stars. In response to why they might choose to watch Chinese content, the most cited response was some personal relationship with China, for instance studying the language, an interest in Chinese culture or a business in China. The difficulty of the survey was of course expecting people with no interest in China to respond. In this regard, both this survey and the one conducted by Beijing Normal require us to remain circumspect about reaching conclusions. The most telling survey about cultural soft power, if this could be conducted, would be one conducted on the street with passers-by.

Online reception, for instance sharing of news about stars and films, or dedicated recommendation sites like Douban or Rotten Tomatoes, can inform about trends and sentiment, but it is difficult to equate fan analysis with engagement. ${ }^{x x i x}$ I will return to this issue in the final section. Traditional metrics remain the default in industry analysis. Television provides a different benchmark of audio-visual exports. Ying Zhu details the international ambitions of China's national television broadcaster, China Central Television (CCTV). ${ }^{\mathrm{xx}}$ Its recent online incarnation China Global Television Network (CGTN), reaches 
out to the world and its channels are accessible in international hotel chains. Many Chinese tourists use these hotels and it is no doubt reassuring to see familiar voices on the screen reminding viewers of China's crackdowns on corruption, rising living standards and international influence. However, despite the tie-ins with hotel chains, the reception of Chinese television among foreign audiences is not increasing. Li Huailiang, an expert on China's foreign cultural trade, has criticized inherent problems, such as uniformity in content and concentration in certain markets. Chinese television, for instance, is concentrated in the United States, Canada, Singapore, Hong Kong, and Taiwan. ${ }^{\text {xxi }}$ In these markets, viewers are predominantly overseas Chinese. Most growth has occurred in Taiwan, Hong Kong, and South Korea where TV drama sales have constituted the bulk of the market. How the antiMainland political fervour in Hong Kong, beginning in June 2019, plays out on audience reception remains to be seen.

State data on official sales of Chinese television programs from 2008 to 2016 clearly show the challenges of breaking into non-Asian markets. The Taiwanese market, where Mandarin is spoken, remains the strongest performer, while there has been growth in Japan and South Korea. European, African, and US markets have not shown growth: between 2008 and 2016, sales of TV programs (all genres) to Europe remained low, as was the case in US and African markets. ${ }^{\text {xxxii }}$ Access is not the issue. The Asian content-streaming site Viki, which is headquartered in San Francisco offers a limited buffet of Chinese content; elsewhere content is accessible with digital subscription services using set-top boxes (modems). In Singapore, a nation-state with a Chinese speaking majority, Chinese drama and variety content are provided on free-to-air channels such as MediaCorp Channel 8 and Channel U or on Toggle.sg, a freemium over-the-top (OTT) service related to MediaCorp. In addition, paytv channels from China such as Shen Zhou TV, CCTV4, Dragon TV, and NOW are available via subscription services bundled by Starhub or Singtel. Other dedicated streaming platform choices include Viu, iflix, and Netflix. Even in Singapore, Chinese content is far less popular among the younger demographic than South Korean. Viewers of Chinese drama tend to be middle-aged.

Chinese television has been most successful in Asia, capitalising on an interest in reenactments of history. How then does Chinese history fare in the west? When Netflix entered in an association with iQIYI in 2015 and reformatted the successful serial Empresses in the Palace (zhenhuan zhuan) for their international audiences, the response was underwhelming ${ }^{\text {xxxiii }}$. The problem was twofold; first, most Chinese speaking audiences had already seen the original 76-episode version; second, the reformatted version (six 90 minutes episodes) left out a lot of the story, perhaps to make it more palatable for Western audiences. While the complexity of the story and its allusions to contemporary society were attractive to Chinese mainlanders and persons with significant Chinese cultural literacy, such subtleties were lost in translation and in the process of reformatting for Netflix consumption. Adding to cultural dissonance is the omnipresent reality of propaganda.

The 'ideas' entailed in China's audio-visual goods and services are for the most part reflective of a partisan ideological position, hardly surprising when we consider the fact that all media producers are shackled by political responsibilities. As Wendy Su notes, filmmakers may challenge the ideological orthodoxy by choosing topics that are critical of society or deal with taboo issues. ${ }^{\text {xxiv }}$ The target may be foreign critical acclaim rather than 
financial reward in the domestic market. Directors like Jia Zhangke and Zhang Yuan are among a small number whose work has found critical acclaim abroad. Filmmakers will take the road of least resistance, avoiding direct critique of the political system. Television dramas regularly dispense revisionist histories about China's wars against the Guomindang and the Japanese. The government believes that propaganda should be consistent and frequently administered; for instance, television serials constantly remind people of the cruelty of the Japanese during the 1930s and 1940s. Such serials resonate with middle-aged viewers and patriots in particular. It is implausible to think that this genre might be exported to Japan without leading to a major diplomatic crisis.

When media foreign players enter China, including Hollywood majors, we observe the practice of tailoring films for the Chinese audience, and by default its government (the censors), films that have Chinese actors and locations, and which don't criticize the regime. As one critics puts it: 'With a business model that relies on exporting American films, Hollywood imports foreign censorship. ${ }^{\mathrm{xxxv}}$ The question is: do these kinds of movies appeal to the discerning Chinese audience, the younger, hipper constituency that frequent Douban to find out about foreign films, or do they play instead to an imagined mainstream audience?

For China's media industries that are keen to answer the call of government, the key question is: how can they make inroads into the western market? Should China be concentrating on action blockbusters? Should Chinese film makers learn about story-telling from the successes of foreign content in China? Unfortunately, the state regulators ${ }^{\mathrm{xxxvi}}$ have a habit of intruding into the cultural sphere, which impacts on a lot of co-production projects that might help change China's image; for instance, one would hope that China produce a film like Clint Eastwood's Absolute Power, about a corrupt president [perhaps not so fictional], or The Post, the recent depiction of the Watergate scandal. The reason that US soft power has achieved a degree of potency is in no small part due to its ability to reflect civil society, and to criticize the abuse of power by its government.

Yingchi Chu notes the West's capacity 'not only for critique but also for auto-critique, systematic self-criticism. ${ }^{\text {xxvii }}$ Chinese audiences are served Wolf Warrior 2 and the big budget TV drama, In the Name of the People (renmin de mingyi) about the heroics of China's law enforcement men and women. Where Chinese film and television culture does manage to offer a critique of its own polity it usually does this by analogy, through depictions of the past that might be construed as providing a lesson for the present. While capturing the eyeballs of those who understand the workings of Chinese politics, these kinds of stories do not reach out to the global audience. Chu further maintains that the 'horizons of expectation' between Western and Chinese audiences are different and the former have difficulty reading Chinese texts. Can this change?

\section{Digital platforms: the rising tide}

The answer to this is probably in the negative, in the short term at least. Paradoxically, the reluctance to change is due to the fact that Chinese film and television are reaching out to increasing numbers on online platforms such as Youku Tudou, iQIYI, Tencent Video etc, and audiences are sharing content on messaging platforms such as WeChat. This success in connecting to audiences mitigates against changing the way that content is made; if time- 
honoured narrative formats work then why change them? Change is more obvious in realitystyle content, which is increasingly introducing elements from outside the mainland, for instance from Taiwan, South Korea, Malaysia. The people using Chinese digital platforms are part of a linguistic community: speakers of Chinese. Arguably such online distribution reinforces existing consumption patterns and mitigates against innovation.

Digital platforms are thus serving a dual function: they distribute Chinese-made content far and wide and at the same time they familiarize Chinese audiences with foreign content and celebrities. The latter function is important insofar as it creates an appetite for novelty, for formats and genres that are fresh. Whereas the traditional media system was charged with educating the population about history and China's changing society, the digital world has opened China up to pop culture, including Asian pop. ${ }^{\text {xxxiii }}$ When internet access exploded in China in the early 2000s it provided a new frontier for creative content; in particular it has been, and still is to some extent, an oasis for foreign produced and user generated content (UGC). It served to 'connect' Chinese audiences, particularly youth audiences, to the world. Having access to world content reminded audiences of the unprofessional and propagandist nature of much that is served up on local screens. While alternative (foreign) content was available to users via China Telecom's VNET portal in $2002^{\text {xxxix }}$ the launch of the bit torrent site BTChina in 2003 precipitated a flood. Its popularity then spawned pirate sites. The main target of downloading activity was Hollywood films and US, European, Japanese and Korean TV serials. These were widely redistributed. Second screens (mobile, tablet) where one could view, participate and share privately, soon became available. Online video sites thus became alternative distribution channels for content that was not permitted on existing state networks, made possible because of faster broadband and better file-sharing technologies.

Prior to 2008 the online video world was loosely regulated. In December 2007, the Administrative Provisions on Internet Audio-Visual Program Service caused most BT websites to close down, including top destinations such as BTChina.net and bt.ydy.com. The vacuum was filled approved operators. By December 2009, SARFT had granted 332 licenses to online video service providers ${ }^{\mathrm{xl}}$; the majority were state-owned TV stations, radio stations, and news media at national, provisional, and local levels. Some private companies were also on the list, including leading players Tudou and Youku. With the Provision stipulating that only wholly state-owned or state-held corporations can apply for the license, personal websites without a corporate capacity were among the first to disappear. While the news was bleak for the file-sharing community, it created opportunities for entrepreneurs with deep pockets and good connections.

The rapid uptake of online content is partly attributable to the availability of foreign content online, especially during the so-called 'good times' of free downloads. This appetite persists, although these days people are more prepared to pay, at least for content that is unique, interesting, popular, and creative. Online content is generally more diversified than traditional formats which are characterized by their ideological orthodoxy. In this way, the digital revolution has positioned CEOs of China's leading digital media companies as agents of change: some are advisors to the government's innovation agenda, and in many instances, they perform as media industry celebrities. For these industry leaders, their companies' expansion into content industries is a smart move, designed not to make a profit from online 
video and film industry financing, but as a way of building loyalty among China's legion of young net users. Furthermore, it enhances both their charismatic appeal and their celebrity status, both which are 'attributions' of power.

Earlier I discussed the term 'cultural empowerment'. I now suggest this has two aspects: the personal empowerment of the new digerati class, and the cultural empowerment mission of the state, known as 'going out'. The way to activate the 'going out' mission now seems to be more than ever digital. Digital platforms provide a way to reach out instantaneously. The rise of the internet tech companies therefore offers a somewhat different perspective on China's ability to extend its ideas - and ideology - into new territories. In China today the term BAT is synonymous with Baidu, Alibaba and Tencent, known as the 'three kingdoms.' To this power trident we can add 'W', Dalian Wanda, Wanda, the film industry behemoth from north-eastern Qingdao, headed up by Wang Jianlin who contests the honour of being China's richest person with Jack Ma of Alibaba. While Wanda has focused on movie production and co-productions, it now has ambitions in the online distribution space. In 2015, Wang Jianlin presented a talk at Harvard University, called 'Going Globalthe Wanda Way', in which he spoke of four stages in the company's transformation. The first was to venture outside of Dalian becoming a national company; the second was to become a real estate company with global assets; the third stage saw Wanda moving into the cultural and tourism sectors; the fourth stage according to Wang is to go global. He said, 'We will try to make Wanda a spokesperson for Chinese companies going abroad.' A more pointed comment followed in an interview when he said: 'private companies that go global to expand their business are answering the call from government. ${ }^{\text {xli }}$

In effect, these companies are riding the digital wave of China's $13^{\text {th }}$ Five Year Plan with its explicit endorsement of the 'digital creative industries' (shuzi chuangyi chanye). However, it's probably best to see these developments as a reflection of global business empires. Baidu is China's equivalent of Google, Alibaba of eBay, while Tencent is a combination of What's App but with a number of innovative social media and payment services. Of the four entities, Alibaba and Tencent are pushing ahead in content-related businesses while Baidu is falling behind. Meanwhile, Wanda is experiencing the whims of operating in a nation where good government relations are paramount. In the past the company had close connections with the government, Wang himself being a former PLA officer. The situation now is somewhat tenuous. Once touted as a Chinese heavyweight champion, Wang's empire is in danger of imploding. The company invested heavily in a massive film studio in Qingdao as well as theme parks, including proposed Chinese cultural theme parks along the Eurasian One Belt One Road. It acquired AMC cinemas in North America in 2012 and Hoyts cinemas in Australia in 2015. Talk at the time was about how this would upgrade China's soft power capabilities, given that these cinema chains would promote Chinese films. The acquisition of Hollywood studio, Legendary Pictures was a coup for the Chinese film industry. However, recent moves by Xi Jinping to rein in overseas investment deals, particularly in the light of trade tensions with the US, have forced Wanda to move its focus back to the mainland. This is another side to the expression 'answering the call to government.' 


\section{Concluding discussion: The rise of social media entertainment}

There is no doubt that China's position in the world has changed. Its ascendency, particularly in its region, and in territories like central Asia and Africa, is tied to the 'going out' of industrial heavyweights such as steel, energy, machinery and construction. ${ }^{\text {xlii }}$ The 'going out' of China's culture, however, remains a work-in-progress. This paper has examined how consumers are engaging with Chinese content beyond national boundaries, finding that success remains limited and largely sequestered within diasporic communities. Chinese people in the world have unprecedented access to information from the mainland. Chinese online platforms reach out to Chinese speakers, offering them a chance to be part of the great rejuvenation. ${ }^{\text {xliii }}$ Preaching 'to the converted' in the Chinese diaspora, however, may in the end eschew the kind of creative risk taking that has seen Hollywood become the media capital of the world. Because market success is assured, there is a disinclination among many in the industry to change the way content is made. Adding to this national content focus, is the escalation of the China US trade dispute under Donald Trump, which has impacted on the willingness of both nations to collaborate in film making, for the present time at least.

The question of how effectively China's film and television industries contribute to China's international reputation also remains unclear. Reports that viewers in developing countries are warming to Chinese TV serials for instance, usually in Chinese state media, need to be balanced by a reminder of the continued dominance of Korean pop culture in many parts of the East and South-east Asian region. Yet the view that Hollywood or K-Pop is representative of media production success is changing. Stuart Cunningham and David Craig have presented a powerful thesis that that established players that have dominated screen industries in the twentieth century are ceding significant power and influence to digital streaming and social networking platforms. They call this phenomenon 'social media entertainment'. xliv As mentioned earlier, the question of engagement then arises; how do users engage online? Findings from this research suggest that traditional industry boundaries are changing and more content is coming from online platforms, often produced by amateurs.

The other challenge to the film and TV industries also comes from within. Along with the rise of hybrid content and social networking platforms - such as podcasts, vlogs and usergenerated content, is the emergence of Internet-distributed television portals such as Hulu, Netflix, Amazon Video and Apple's iTunes, and in China entities like iQIYI, Tencent Video, Youku and Bilibi. As noted in this paper, iQIYI and Netflix have sought to collaborate. In many respects, Chinese platforms like iQIYI need licensed overseas content for their discriminating young audiences more than Netflix needs Chinese language content. The latter is perhaps more a case of supplementing its offerings to be more representative of foreign content. Chinese-speaking audiences outside China meanwhile are easily accessing content from iQIYI, Tencent Video, Youku and Bilibi, as well as video on demand (VOD) platforms like Viu, KanTV, Duonaolive, and Viki, and as noted in our survey results, from YouTube. Indeed, if one of the most successful platforms for viewing Chinese language content overseas is one, YouTube, where a large proportion of content is uploaded by non-industry professionals, can this be really considered a successful case of 'going out'? 


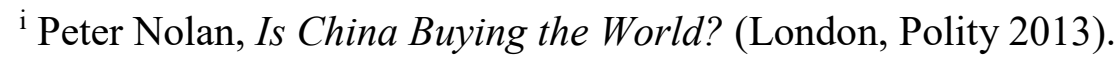

${ }^{i i}$ For a discussion see Yu Hong, Networking China: the Digital Transformation of the

Chinese Economy. (Urbana, University of Illinois Press, 2017).

iii See Huailiang Li, 'Chinese culture 'going out': an overview of government policies and an analysis of challenges and opportunities for international collaboration', in Michael Keane (ed.) The Handbook of Cultural and Creative Industries in China. (Cheltenham: Edward Elgar), $129-143$.

iv David, Shambaugh, China Goes Global: The Partial Power. (Oxford, Oxford University Press, 2013)

v “To sum up, so far as China's peaceful rise is concerned, it is only a cherished "Chinese dream" based on China's national condition and it aims at solving China's own problems, but certainly not any other dream. Speech China's rise is a peaceful rise. The rejuvenation of the Chinese Nation is the rejuvenation of its civilization - speech at the Beijing Regional Conference of the Asia-Pacific Working Group of the "Trilateral Commission" (November 25, 2005), Bijian, Zheng. China's Road to Peaceful Rise. (London, Routledge, 2011)

${ }^{v i}$ Chua Beng-Huat, Structure, Audience and Soft Power in East Asian Pop Culture (Hong Kong: HKU Press, 2012); Dal Yong Jin, New Korean Wave: Transnational Cultural Power in the Age of Social Media. (Urbana, University of Illinois Press, 2016); Davis, Darrell, and Emilie Yueh-Yu Yeh. East Asian Screen Industries. (Berkshire: BFI Palgrave, 2008).; Anthony Y.H. Fung (ed.). Asian Popular Culture: The Global (Dis)continuity. (Routledge: London, 2013).

vii Wanning Sun, 'Slow boat from China: public discourses behind the 'going global; media policy', International Journal of Cultural Policy 21 (2015), 4: 400 - 418 
viii Yuezhi Zhao $(2013,21)$ Yuezhi Zhao. 2013. “China's Quest for 'Soft Power': Imperatives, Impediments and Irreconcilable Tensions? ” Javnost - The Public 2 (2013) (4), 21.

ix Shen Zhuanghai, The Chinese Logic of the Construction of Cultural Power (wenhua qiangguo jianshe de Zhongguo luoji) (Beijing, Peoples' Publishing House, 2017).

${ }^{x}$ See Joseph S. Nye Jnr., Bound to Lead: the Changing Nature of American Power. New York, NY: Basic Books, 1990

${ }^{x i}$ Nye, Bound to Lead; Gary Rawnsley 'To Know Us is to Love Us: Public Diplomacy and International Broadcasting in Contemporary Russia and China' Politics 35, no. 3-4 (2015): 273-286; Terry Flew, "Entertainment Media, Cultural Power, and Post-globalization: the Case of China's International Media Expansion and the Discourse of Soft Power" Global Media and China 1, no. 4 (2016): 278 - 294. xii Ying Zhu, Two Billion Eyes: The Story of China Central Television. New York, NY, The New Press, 2012

xiii Wendy Su, China's Encounter with Global Hollywood: Cultural Policy and the Film Industry 1994 - 2016 (Lexington, University of Kentucky Press, 2016)

xiv SARFT is now called National Radio and Television Administration (NRTA). For a discussion see Michael Keane, The Chinese Television Industry. London, Palgrave BFI, 2015. ${ }^{\mathrm{xv}}$ Michael Keane, Created in China: The Great New Leap Forward (London, Routledge, 2007); Michael Keane, Creative Industries in China: Art, Design, Media (London, Polity, 2013)

${ }^{x v i}$ Zitong Qiu, 'Doing Chinese cultural industries: a reflection of the Blue Book syndrome and remedy paradigm', in Michael Keane (ed.) The Handbook of Cultural and Creative Industries in China. (Cheltenham: Edward Elgar, 2016), 15 - 26

xvii Stuart Cunningham and David Craig, Social Media Entertainment: the New Intersection of Hollywood and Silicon Valley. (New York, NYU Press 2019)

xviii https://www.nytimes.com/2016/12/22/movies/the-great-wall-what-critics-and-filmgoersare-saying-in-china.html

xix Pamela McClintock, 'Matt Damon's 'The Great Wall' to lose \$75 million: future of USSino co-productions in doubt', The Hollywood Reporter, 3 February 2017, available at https://www.hollywoodreporter.com/news/what-great-walls-box-office-flop-will-coststudios-981602

${ }^{\mathrm{xx}}$ Clifford Coonan, Ying Zhu, Stanley Rosen, Jonathan Landreth, 'Is the search for a China Hollywood blockbuster doomed?' Foreign Policy, China File, 24 Feb 2017, available 
https://foreignpolicy.com/2017/02/24/is-the-search-for-a-china-hollywood-blockbusterdoomed-great-wall-fail/

${ }^{x x i}$ https://www.the-numbers.com/movie/Great-Wall-The/South-Korea\#tab=summary

xxii https://www.rogerebert.com/reviews/wolf-warrior-2-2017

xxii Wendy Su, China's Encounter with Global Hollywood, 159.

xxiv Huiling Huang, Zikai Sun, Chao Wang and Zhuofan Yang, 'Zhongguo dianying yu guojia yingxiang chuanbo (Chinese film and the communication of national image', Xiandai chuanbo (Modern Communication) 1: 22- 28.

${ }^{\mathrm{xxv}}$ Chris Berry, 'Transnational culture in East Asia and the logic of assemblage.' Asian Journal of Social Science 41, 5 (2013): 453-70.

xxvi Kaihao Wang, 'Survey shows Chinese movies gain ground in North America', The China Daily, accessed 15 May, 2018 at http://usa.chinadaily.com.cn/a/201803/22/WS5ab2ed3aa3106e7dcc145550.html xxvii Wendy Su, China's Encounter with Global Hollywood, 159. xxviii The survey is part of a research project (ongoing at time of writing), called Digital China: from Cultural Presence to Innovative Nation. The survey was still open at time of writing and for this reason I have not provided the full data. The survey also asked the question 'where are you living now' in order to capture a sense of perspective, as we found that many Chinese respondents were living or studying overseas (in HKSAR and Australia in particular). Because the survey was distributed through several sites, including the Chinese social media site WeChat, $55 \%$ of responses (513) came from persons who were born and were living in the PRC. These were discounted in the analysis as the main purpose of the research was to ascertain non-Chinese views

${ }^{x x i x}$ For a discussion of engagement in relation to international television series in China see Filippo Gilardi, Celia Lam, K Cohen Tan, Andrew White, Shuxin Cheng and Yifan Zhao, 'International TV series distribution on Chinese digital platforms: marketing strategies and audience engagement' Global Media and China 32018 (3) 213230doi/10.1177/2059436418806406

xxx Ying Zhu, Two Billion Eyes: The Story of China Central Television. New York: The New Press, 2012)

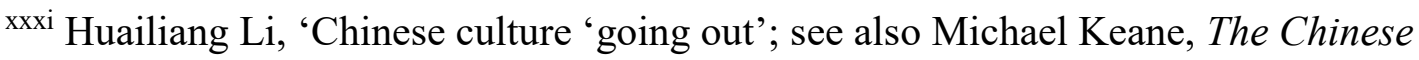
Television Industry, pp. $69-72$

xxxii In 2008, sales of TV programs in Europe were US\$2.53 million, in the United States US\$1.64 million, and in Africa US\$0.41 million. In 2016, the numbers were US\$2.90, 
US\$2.03, and US\$0.36 million, respectively. Source:

http://www.stats.gov.cn/tjsj/ndsj/2017/indexch.htm; Michael Keane, The Chinese

Television Industry, 70-71

xxxiii 'Empresses in the Palace flops in North America', China Daily 23 March 21065, available at http://www.chinadaily.com.cn/culture/2015-03/23/content_19884401.htm xxxiv Wendy Su, China's Encounter with Global Hollywood xxxv Conor Sen and Megan McArdle, 'Saving Hollywood from the Chinese Box Office', Interview 11 Jan 2018, available at https://www.bloomberg.com/view/articles/2018-0110/saving-hollywood-from-the-chinese-box-office xxxvi The regulators here include the Publicity Department, formerly known as the Propaganda Department, which has taken responsibility from SARFT in 2018; other regulatory agencies include the China Film Coproduction Corporation (CFCC), which might recommend projects.

xxxvii emphasis in original, Yingchi, Chu, 'The politics of reception: 'Made in China' and western critique'. International Journal of Cultural Studies 17 (2014), 2: 170. xxxviii Chua Beng-Huat, Structure, Audience and Soft Power in East Asian Pop Culture (Hong Kong: HKU Press, 2012)

xxxix Nina Luzhou Li 'Rethinking the Chinese internet: social history, cultural forms and industrial formations'. Television and New Media 18 (2016), 5: 393- 409

${ }^{x l}$ Elaine Jing Zhao, and Michael Keane, 'Between formal and informal: the shakeout in China's online video industry'. Media Culture and Society 35 2013, (6) 724 - 741. https://doi.org/10.1177\%2F0163443713491301

xli Jianlin Wang, The Wanda Way. (London, LID Publishing, 2016) 237. xlii Huiyao Wang and Lu Miao, China Goes Global: How China's Overseas Investment is Transforming its Business Enterprises. Basingstoke, Palgrave Macmillan, 2016 xliii Michael Keane, 'Disconnecting, connecting, reconnecting: How Chinese television got out of the box' International Journal of Communication 2016, 10: 5426-5443 xliv Stuart Cunningham and David Craig, Social Media Entertainment: the New Intersection of Hollywood and Silicon Valley. (New York, NYU Press 2019) 